\title{
Interacción de la radioterapia con los nuevos agentes con dianas moleculares
}

\author{
Interaction of radiotherapy and new agents with molecular targets
}

\author{
E. Martínez López, C. Eito, A. Sola, M. Rico, M.T. Vila, V. Chicata
}

\section{RESUMEN}

La radioquimioterapia supuso uno de los mayores logros en el tratamiento del cáncer en las últimas décadas, aunque con una importante toxicidad para los enfermos. La investigación desarrollada recientemente en la biología molecular del cáncer ha permitido conocer los cambios genéticos y moleculares que determinan la transformación maligna celular, lo que ha conducido a identificar moléculas claves convirtiéndolas en dianas moleculares además de revolucionar los conceptos radiobiológicos de respuesta celular a las radiaciones y de radiorresistencia.

Los nuevos agentes contra dianas moleculares poseen mayor especificidad y menos efectos adversos, lo que les hace más atractivos que la quimioterapia para ser combinados con radioterapia. Pueden actuar inhibiendo las señales de transducción intracelular, modulando el ciclo celular, la apoptosis o inhibiendo la angiogénesis. El efecto de la radioterapia puede potenciarse a través de una inhibición de la repoblación celular, mejoría de la oxigenación tumoral, redistribución durante el ciclo celular, inhibición de la invasión y metástasis, y aumento de la radiosensibilidad. Los datos disponibles apoyan su eficacia y aplicabilidad en estudios preclínicos y clínicos en diversos modelos tumorales y abren una vía esperanzadora de cambio en el tratamiento del cáncer.

Palabras clave. Nuevas dianas moleculares. Interacciones con la radioterapia. Radiorresistencia. Radiosensibilidad.

\begin{abstract}
Radiochemotherapy represents one of the greatest achievements in cancer treatment in recent decades, although it involves significant toxicity for patients. Research developed recently in the molecular biology of cancer has enabled understanding of the genetic and molecular changes that determine malign cellular transformation, which has led to the identification of key molecules, converting them into molecular targets that have led to a revolution in radiobiological concepts of cellular response to radiations and radioresistance.

The new agents against molecular targets possess greater specificity and less adverse effects, making them more attractive than chemotherapy for combination with radiotherapy. They can act by inhibiting intracellular transduction signals, modulating the cellular cycle, apoptosis or inhibiting angiogenesis. The effect of radiotherapy can be strengthened through inhibition of cellular repopulation, improvement of tumour oxygenation, redistribution of the cellular cycle, inhibition of invasion and metastasis, and increase of radiosensitivity. The available data support its efficacy and applicability in preclinical and clinical studies in different tumour models and open up a promising path in cancer treatment.
\end{abstract}

Key words. New molecular targets. Interactions with radiotherapy. Radioresistance. Radiosensitivity.
Servicio de Oncología Radioterápica. Hospital de Navarra. Pamplona.

\author{
Correspondencia \\ Enrique Martínez López \\ Servicio de Oncología Radioterápica \\ Hospital de Navarra \\ Irunlarrea, 3 \\ 31008 Pamplona. Navarra
}

Tfno. 848428475 


\section{INTRODUCCIÓN}

Durante los últimos años se ha realizado un enorme trabajo de investigación que ha permitido incrementar abundantemente nuestros conocimientos acerca de los cambios genéticos y moleculares que determinan la trasformación maligna de células normales. Hanahan y Weinberg describieron en el año 2000 esos cambios, que incluyen la regulación de la señal de transducción, diferenciación celular, apoptosis, reparación del ADN, progresión del ciclo celular, angiogénesis y adhesión celular ${ }^{1}$.

El conocimiento de esas alteraciones específicas y de sus mecanismos reguladores ha permitido a los investigadores identificar una serie de moléculas claves y convertirlas en dianas terapéuticas. El rápido desarrollo de nuevos fármacos dirigidos contra esas dianas es actualmente un área prometedora de tratamiento contra múltiples enfermedades malignas. Por definición, su especificidad antitumoral es superior a la de la quimioterapia (QT) y sus efectos adversos son menores y diferentes. La eficacia de estos nuevos agentes se ha puesto ya de manifiesto en diversos tumores, incorporándose a las estrategias terapéuticas clásicas con quimio o radioterapia (RT) o incluso desplazando en algún caso a la QT como primera línea de tratamiento ${ }^{2}$.

Por otra parte, la aplicación de los conocimientos moleculares tumorales al campo de la radiobiología, ha trasformado en pocos años los conceptos de respuesta celular a las radiaciones ionizantes y de radiorresistencia. Algunos de estos agentes han demostrado ya no sólo capacidad antiproliferativa, sino también efecto radiosensibilizante en modelos preclínicos de cánceres humanos y posteriormente en estudios clínicos ${ }^{3}$. Dado que una proporción ampliamente superior al 50\% de los enfermos oncológicos en el mundo reciben RT como parte de su tratamiento oncológico integral, esta nueva estrategia puede suponer un importante avance en el tratamiento del cáncer.

\section{INTERACCIÓN ENTRE RADIOTERAPIA Y AGENTES CON DIANAS MOLECULARES}

El control tumoral después de administrar RT con intención curativa depende de la posibilidad de provocar la muerte celular de todas las células clonogénicas capaces de promover el recrecimiento tumoral y está influido por la radiosensibilidad intrínseca de las células, por la capacidad que tengan de reparar el daño radioinducido al ADN y por factores microambientales a nivel del tumor y del estroma tisular, como la hipoxia tumoral y la reoxigenación o la proliferación celular capaz de provocar una repoblación acelerada de los clonógenos tumorales supervivientes ${ }^{4}$.

Uno de los objetivos primordiales de combinar RT con otros tratamientos es reducir la radiorresistencia y mejorar así el índice terapéutico. Las estrategias para mejorar el índice terapéutico de la RT fueron descritos hace ya tres décadas y consisten básicamente en incrementar la muerte celular tumoral, reducir la toxicidad en los tejidos normales, utilizar agentes con actividad antitumoral sistémica que puedan controlar la enfermedad fuera del campo de RT y evitar la asociación de tratamientos con toxicidad solapada ${ }^{5}$.

Los agentes contra dianas moleculares reúnen varias de esas condiciones. Algunos de ellos, dadas sus propiedades antiproliferativas, pueden evitar la repoblación tumoral que puede desencadenarse siguiendo la RT, pueden también incrementar el control sistémico de la enfermedad fuera del campo de tratamiento, modificar la radiosensibilidad de algunos tumores y mejorar la reoxigenación a través de la inhibición de la angiogénesis tumoral.

Es importante destacar por último, que a pesar del amplio uso de la radioquimioterapia en las últimas décadas y de su importante aportación al tratamiento del cáncer, el principal problema de esta combinación radica en el aumento de la toxicidad radioinducida aguda y crónica sobre los tejidos sanos provocada por la QT. En este senti- 
do, la mayor espeficidad de acción de los nuevos agentes contra dianas moleculares y su favorable perfil de toxicidad produce un escaso solapamiento de efectos secundarios con la RT ofreciendo ventajas potenciales en relación a la QT.

\section{DIANAS MOLECULARES ESPECÍFICAS Y RADIOTERAPIA}

La información derivada de la investigación destinada a identificar dianas moleculares y agentes eficaces contra ellas, capaces al ser combinados con RT de modificar la radiosensibilidad, los mecanismos de reparación celular, la reoxigenación, la redistribución y repoblación es tan extensa, que supera ampliamente las pretensiones de este trabajo. Las tablas 1 y 2 recogen los agentes con los que más experiencia se ha conseguido, anticuerpos monoclonales y moléculas de bajo peso molecular, sus dianas y sus indicaciones clínicas. En este trabajo se atiende a las vías moleculares mejor estudiadas y los agentes que han demostrado hasta el momento mayor utilidad al ser combinados con RT, tanto en ensayos preclínicos como clínicos.

Tabla 1. Anticuerpos monoclonales.

\begin{tabular}{|l|l|l|}
\hline \multicolumn{1}{|c|}{ Agente } & \multicolumn{1}{c|}{ Diana } & \multicolumn{1}{c|}{ Indicación clínica } \\
\hline Trastuzumab (Herceptin $\left.{ }^{\circledR}\right)$ & ErbB2 & CM \\
\hline Cetuximab (Erbitux®) & EGFR & CCC, CCR \\
\hline Bevacizumab (Avastin $®)$ & VEGFR & CCR, CM \\
\hline Panitumumab & EGFR & \\
\hline Pertuzumab (Omnitarg®) & ErbB2 & \\
\hline
\end{tabular}

CM: cáncer de mama. CCC: cáncer de cabeza y cuello. CCR: cáncer colorrectal.

Tabla 2. Moléculas de bajo peso molecular.

\begin{tabular}{|c|c|c|}
\hline Agente & Diana & Indicación clínica \\
\hline Erlotinib (Tarceva®) & EGFR & CPNM, CP \\
\hline Grefitinib (Iressa®) & EGFR & CPNM \\
\hline Imatinib (Glivec®) & PDGFR, Abl, c-kit & LMC, GIST, DP \\
\hline Sorafenib (Nexavar®) & VEGFR, PDGFR, c-kit, B-raf, Raf-l & CRCC \\
\hline Sunitinib (Sutent ${ }^{\circledR}$ ) & VEGFR, PDGFR, c-kit & CRCC, GIST \\
\hline Temsirolimus (Torisel®) & m-TOR & CRCC \\
\hline Lapatinib (Tycerb®) & EGFR, Erb B2 & \\
\hline Tipirfanib (Zamestra®) & Farnesiltransferasa & \\
\hline Marimastat & MMP & \\
\hline
\end{tabular}

CPNM: cáncer de pulmón no microcítico. CP: cáncer pancreático. LMC: leucemia mieloide crónica.

GIST: tumor del estroma intersticial. DP: dematofibroma protuberante. CRCC: cáncer renal de células claras.

\section{PROLIFERACIÓN CELULAR}

Una de las respuestas celulares más precoces a la irradiación es la activación de vías de señalización responsables del control de genes que promueven la supervivencia celular, a través de una rápida proliferación celular, inhibición de la apopto- 
sis, aumento de la invasión, angiogénesis, metástasis y de mecanismos de resistencia a la RT y a otros tratamientos.

\section{EGFR. Interacción con la Radioterapia}

Las señales proliferativas se trasmiten al interior de la célula, habitualmente a través de receptores transmembrana, a los que se unen para su activación factores de crecimiento en la superficie de la membrana. Los factores de crecimiento son moléculas efectoras de proliferación celular, diferenciación, adhesión, supervivencia y migración. El receptor del factor de crecimiento epidérmico o EGFR fue uno de los primeros caracterizados y el más ampliamente estudiado. Pertenece a una familia de cuatro receptores transmembrana íntimamente relacionados, conocida como familia ErbB o HER ( $\mathrm{Hu}$ man epidermal growth factor), mostrando una alta homología entre sus miembros. El más representativo de todos ellos es EGFR o ErbB1 y el resto son ErbB2 o HER2, ErbB3 y ErbB4. Se encuentran habitualmente como monómeros en la superficie celular y están constituidos por un dominio extracelular con el que se unen al ligando, un dominio transmembrana y un dominio intracelular con actividad tirosinkinasa. La activación de estos monómeros al unirse con un ligando produce dímeros (homo o heterodímeros). Se han reconocido al menos diez ligandos para este grupo de receptores siendo los principales el factor de crecimiento epidérmico (EGF) $\mathrm{y}$ el factor trasformador de crecimiento alfa (TGF-alfa). Las señales a través del EGFR se inician cuando un ligando se une a un monómero ErbB desencadenando la dimerización y ulteriormente la autofosforilación de los residuos de tirosina en la región carboxiterminal del dominio intracelular, permitiendo así el anclaje de proteínas señalizadoras y la activación de múltiples vías de señalización intracelular, siendo las más importantes Ras/Raf/ MAPkinasa, Jat/Stat y PI3K/Akt. Finalmente todo ello conduce a la transcripción en el núcleo de genes implicados en potenciar la supervivencia celular por inhibir la apoptosis o promover la proliferación, la angiogénesis, la invasión y las metástasis ${ }^{1}$.

La hiperactivación de los receptores transmembrana y de sus vías de señalización conllevan un comportamiento más agresivo de diversos tumores, lo que explica que estos receptores hayan sido considerados como importantes dianas terapéuticas. EGFR está relacionado con el desarrollo y proliferación de tumores de cabeza y cuello, pulmón, páncreas, mama o vejiga ${ }^{6}$ ErbB2 está sobreexpresado el $25 \%$ de las pacientes con cáncer de mama y se asocia a peor pronóstico. Este hecho lo ha convertido en una importante y rentable diana terapéutica. Los tumores que sobreexpresan los dos receptores presentan peor pronóstico que los que sobreexpresan sólo uno?

La exposición a la radiación provoca la muerte celular por medios físicos debido a la acumulación de daños letales al ADN. EGFR está implicado de un modo importante en el desencadenamiento de respuestas de supervivencia que siguen a la irradiación. Se sabe que altos niveles de EGFR en un tumor son predictivos de radiorresistencia y de mayor probabilidad de recaída después del tratamiento ${ }^{8}$.

Se han propuesto tres mecanismos por los cuales EGFR puede provocar radiorresistencia:

1. Pequeñas dosis de radiación pueden producir la transcripción de genes de respuesta inmediata, incluido EGFR, que activan el receptor.

2. Activación de ligandos que a su vez producen una activación del receptor inducida por ligando.

3. La radiación inactiva fosfatasas que actúan como inhibidores del dominio intracelular tirosinkinasa manteniendo el receptor inactivado.

Algunos estudios han demostrado que la radiación puede activar de una forma indiscriminada todos los miembros de la familia ErbB ${ }^{9}$, favoreciendo la formación de heterodímeros que determinan a su vez la 
activación de vías claves en la señalización intracelular como PI3K/Akt y mTOR, fuer- temente implicadas en los mecanismos de supervivencia celular (Fig. 1).

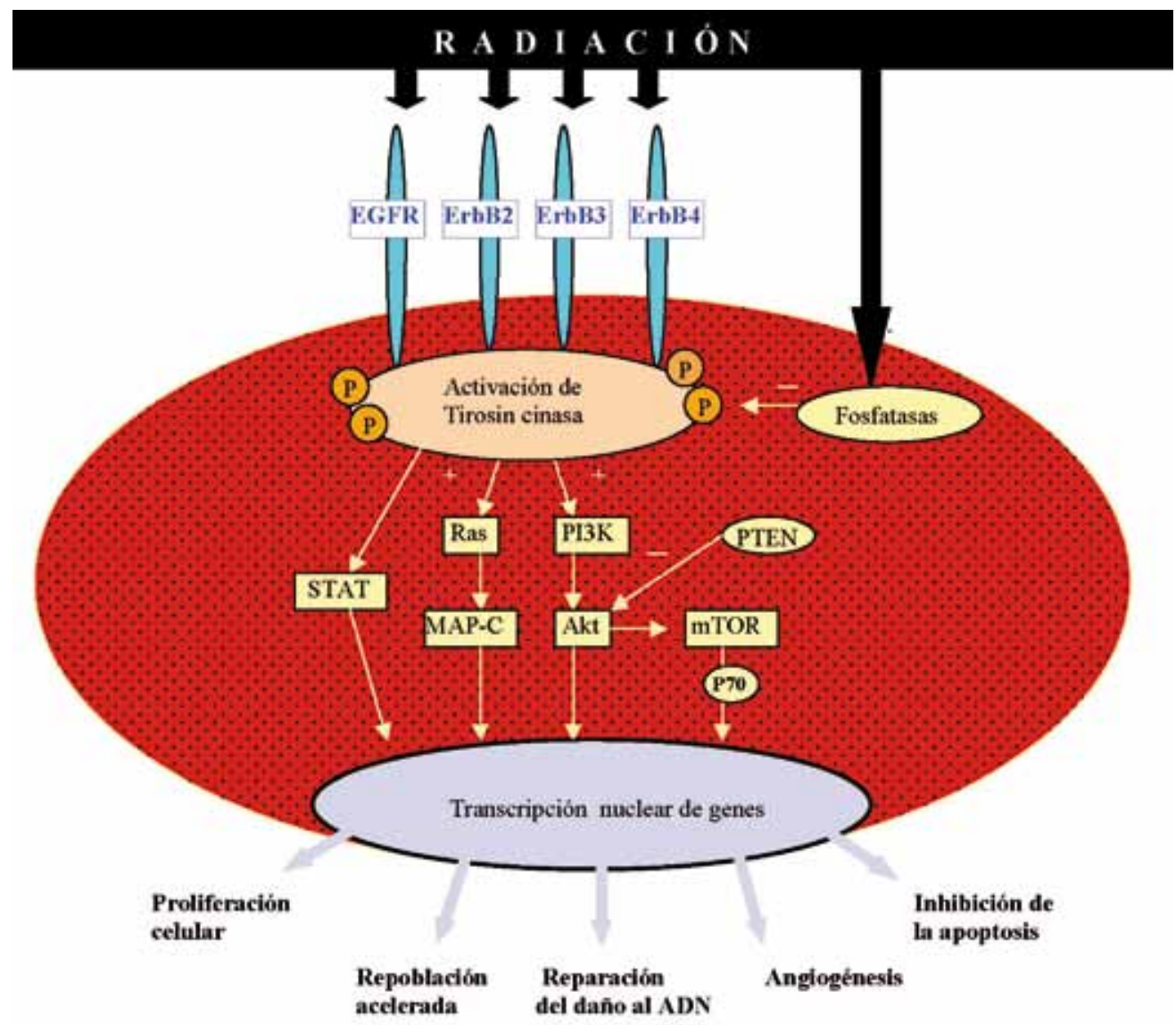

Figura 1. Mecanismos de activación de los receptores ErbB y de sus vías de señalización inducidos por la radiación, determinando respuestas de supervivencia celular y radiorresistencia.

Resulta también destacable que EGFR haya sido localizado en el núcleo celular después de la irradiación, probablemente modulando la transcripción de genes al margen de las vías de conducción de señales habituales.

ErbB2 también está involucrado como agente causal de radiorresistencia ${ }^{10}$ y aunque no existe demostración tan clara para ErbB3 y ErbB4, se considera que también participan en estos procesos ${ }^{11}$.

El resultado de todas estas reacciones es la progresión del ciclo celular, repo- blación acelerada, reparación del daño al $\mathrm{ADN}$, angiogénesis e inhibición de la apoptosis, lo cual se opone a los efectos pretendidamente curativos de la RT.

\section{INHIBIDORES DE EGFR EN ASOCIACIÓN CON RADIOTERAPIA}

\section{Datos preclínicos}

In vitro, el bloqueo de EGFR se sigue de un aumento de la apoptosis inducida por RT, lo que provoca una radiosensibili- 
zación sinergística, que puede ser mayor cuando se utilizan estrategias dirigidas simultáneamente contra EGFR y contra reguladores de las vías de señalización como PI3K y MEK. Los datos in vivo en modelos animales, también demuestran una interacción positiva entre los inhibidores de EGFR y RT.

Este sinergismo se ha observado al utilizar tanto anticuerpos monoclonales dirigidos contra el dominio extracelular del receptor, impidiendo su activación por el ligando, como con moléculas de bajo peso molecular que inhiben la autofosforilación en el dominio tirosinkinasa intracelular. De estos agentes los más estudiados han sido el anticuerpo monoclonal quimérico cetuximab y los inhibidores tirosinkinasa, gefitinib y erlotinib.

\section{Cetuximab}

Es un anticuerpo monoclonal con mayor afinidad por EGFR que sus ligandos naturales, inhibiendo de forma competitiva su unión. Bloquea la dimerización del receptor, la fosforilación de los residuos de tirosina y las señales de transducción. In vitro ha mostrado de forma repetida que incrementa la apoptosis inducida por radiación e inhibe la reparación del daño causado al ADN. In vivo, el tratamiento de carcinomas de células escamosas en ratones con cetuximab y radiación produce una potente regresión de estos tumores ${ }^{12}$, muy superior a la que produce cualquiera de los dos tratamientos de forma aislada.

\section{Gefitinib y erlotinib}

Gefitinib y erlotinib son anticuerpos que han producido resultados similares. In vitro, los estudios en líneas celulares humanas de carcinoma escamoso de cabeza y cuello y de carcinoma no microcítico de pulmón han mostrado que estos agentes provocan inhibición de proteínas reparadoras del $\mathrm{ADN}$, incrementan la apoptosis e inducen detención del ciclo celular en fases menos proliferativas (G1), con una reducción concomitante de células en fase
S. In vivo, el tratamiento de tumores de cabeza y cuello implantados en ratones, con erlotinib y gefitinib más irradiación, resulta más eficaz que cada modalidad por separado $^{13}$. Al igual que el cetuximab provocan una significativa inhibición de la angiogénesis y de metaloproteinasas de la matriz moduladas por EGFR, que conducen a una menor capacidad invasiva tumoral.

Todos estos datos unidos han aportado una base suficiente para investigar el efecto de la inhibición de las señales a través del EGFR durante la RT en pacientes.

\section{Datos clínicos}

\section{Cetuximab}

Su eficacia se ha visto reflejada en el tratamiento de diversos tumores, particularmente el cáncer colorrectal (CCR), carcinoma de cabeza y cuello (CCC) y carcinoma no microcítico de pulmón (CPNM) ${ }^{14}$.

Bonner y col publicaron en $2006^{15}$ el estudio más importante realizado hasta el momento evaluando la eficacia de la asociación de RT con fármacos dirigidos contra dianas moleculares y en concreto contra EGFR. Se trata de un estudio aleatorizado fase III internacional, realizado en 424 enfermos con carcinoma de células escamosas de cabeza y cuello localmente avanzado. Se comparó RT a dosis radicales, frente a este mismo tratamiento con cetuximab concurrente. Los resultados mostraron que con una mediana de seguimiento de 54 meses, la mediana de supervivencia de los pacientes que recibieron el tratamiento combinado superó significativamente a la de los pacientes tratados con RT exclusiva (49 frente a 29 meses; $p=0,03$ ). Además, tanto el control loco-regional, como la supervivencia libre de progresión mejoraron significativamente en el brazo de tratamiento combinado, sin que por contrapartida la toxicidad se viera incrementada, salvo por las reacciones transfusionales y el exantema acneiforme provocados por cetuximab.

El anticuerpo monoclonal humanizado h-R3 también ha sido estudiado conjuntamente con RT en pacientes con carcinoma 
de cabeza y cuello ${ }^{16}$, aportando mayor soporte a la posibilidad de combinar agentes anti-EGFR con RT.

Esta vía de investigación clínica se ha extendido a otros tipos tumorales y a otros compuestos. En el carcinoma de pulmón no microcítico (CPNM), varios estudios en marcha están evaluando la seguridad y eficacia de cetuximab y erlotinib asociados a RT (o a radioquimioterapia) ${ }^{17-20}$. El grupo norteamericano RTOG evalúa en un estudio fase II los efectos de cetuximab en asociación con RT y QT en pacientes con CPNM localmente avanzado. En sus resultados preliminares recientemente publicados, los autores concluían que esta combinación no sólo es segura, sino además claramente activa, mejorando cualquier resultado previo de RTOG en este grupo de pacientes, al haber obtenido una mediana de supervivencia de 22 meses y una supervivencia a los 2 años del 49,3\% ${ }^{19}$.

Con erlotinib, cabe destacar un estudio multicéntrico nacional, fase II, aleatorizado, en pacientes con CPNM irresecable y no candidatos a QT, en el que se compara la tolerancia y eficacia de RT y erlotinib concurrente, frente a RT exclusiva. Como en los estudios precedentes, no se ha encontrado un incremento de la toxicidad radioinducida provocada por erlotinib, en tanto que la tasa de respuestas y las curvas de supervivencia favorecen al grupo de tratamiento combinado en resultados todavía preliminares $^{20}$.

Los datos expuestos reflejan la evidencia aún incipiente de la utilidad potencial que ofrece la asociación de los nuevos agentes dirigidos contra EGFR con RT. Una importante carga de información preclínica validada está en vías de ser testada en estudios clínicos de tumores con diferentes localizaciones: gliomas, carcinoma colorectal, mama, ovario, etc.

\section{Vías intracelulares de señalización. Interacción con la radioterapia}

Los resultados del estudio de Bonner han acelerado la investigación clínica en este área con el objeto de identificar nue- vas vías de señalización susceptibles de ser inhibidas en combinación con RT.

Se han definido varias vías implicadas en la resistencia a la radiación incluyendo EGFR, PI3K y Ras. Aunque la mayor parte de la experiencia se ha adquirido con inhibidores de las señales EGFR, también se han desarrollado agentes contra estas otras dianas, administrados solos o con RT. Gran parte de los tumores muestran mutaciones activadoras en Ras/Raf/MAPK, PI3K/Akt, Jat/STAT y mTOR, o mutaciones inactivadoras de reguladores negativos como PTEN, que en todo caso conducen a un estado de proliferación celular descontrolado.

A pesar de la creciente evidencia acumulada, favoreciendo la interacción positiva entre RT e inhibidores específicos de las vías de señalización, existen limitaciones para el empleo de cualquier estrategia que implique un solo agente contra una sola vía. Por un lado la heterogeneidad tumoral supone la existencia potencial de múltiples procesos oncogénicos activos en distintas subpoblaciones celulares, determinando que la inhibición de una sola vía tenga una utilidad limitada. Por otro lado, las células tumorales sufren una importante inestabilidad genética que les permite modificar las vías de crecimiento y supervivencia, permitiéndoles la adaptación y resistencia a un agente determinado. Estos datos y las complicadas interacciones entre las vías de señalización y la respuesta a la radiación, proporcionan base científica suficiente para bloquear simultáneamente múltiples vías de señalización ${ }^{21}$.

Existen dos tipos de agentes con capacidad de actuar sobre múltiples dianas, conocidos como HSP90 (heat-shock protein 90) y HDAC (histone deacetylase inhibitors). Tanto estos compuestos como determinados agentes contra una sola diana se encuentran bajo intensa investigación tanto preclínica como clínica en estudios fase I/ II.

\section{Inhibidores de la HDAC}

El mecanismo de acción de estas sustancias, inhibiendo múltiples vías de resis- 
tencia a la radiación, proporciona la posibilidad de mejorar la respuesta a la RT. La experiencia preclínica y clínica apunta a que estas sustancias regulan a la baja la expresión de EGFR y ErbB2, inhiben las señales PI3K/Akt y modulan también a la baja proteínas encargadas de la reparación del ADN.

\section{Inhibidores de HSP90}

Generan degradación de algunas proteínas claves implicadas en la radiorresistencia como EGFR, ErbB2, Raf 1 y Akt. Han demostrado capacidad para aumentar la respuesta a la radiación tanto in vitro como in vivo en gliomas, cáncer de próstata, cérvix, colon y pulmón ${ }^{22}$.

\section{Inhibidores de la vía PI3K}

La activación de PI3K/Akt contribuye poderosamente a la radiorresistencia y es por tanto una diana valiosa para intentar potenciar la radiosensibilidad. La activación de esta vía puede estar provocada por amplificación de genes que codifican la subunidad p110alfa de PI3K o más frecuentemente por la mutación del supresor tumoral PTEN. En tumores con una elevada actividad PI3K por inactivación de PTEN, como el glioblastoma (GB), cáncer renal de células claras (CRCC), de mama (CM) o de endometrio, mTOR es un regulador atractivo como diana terapéutica. En el GB, un tumor altamente radiorresistente, se considera que la inactivación de PTEN juega un papel clave provocando señales continuas a través de la vía PI3K que conducen a una rápida proliferación tumoral. Los inhibidores de mTOR, tensirolimus, everolimus, así como RAD001 se encuentran en investigación en estudios fase I/ III ${ }^{21}$. Inducen la parada del ciclo celular en G1.

\section{Inhibidores de la farnesiltransferasa}

Ras y sus proteinkinasas efectoras Raf y MEK también se encuentran hiperactivadas en un $30 \%$ de tumores y son investigadas como dianas. Ras para su activación requiere la adición de un residuo lipídico aportado por la enzima farnesiltransferasa. Algunos inhibidores de esta enzima se encuentran en estudio utilizados solos o en combinación con RT. La mayor experiencia, aunque muy preliminar, se está obteniendo con tipifarnib y lonafarnib ${ }^{23}$.

\section{ANGIOGÉNESIS}

Desde que Folkman ${ }^{24}$ postuló la relación crítica existente entre neurovascularización y crecimiento tumoral, ha quedado establecida la necesidad que tienen los tumores para crecer y expandirse de la formación de nuevos vasos. La angiogénesis tanto fisiológica como tumoral responde a una serie de factores contrapuestos pro y antiangiogénicos, que en el caso de la tumorigénesis están claramente descompensados a favor de los primeros. Estos factores proangiogénicos están producidos por las propias células tumorales o por células de la estroma (células endoteliales, fibroblastos, pericitos o células del músculo liso). El más potente es el factor de crecimiento del endotelio vascular (VEGF). Éste se une a receptores presentes en las células endoteliales (VEGFR1 y VEGFR2), para dirigir la neovascularización del tumor primario y de las metástasis, promoviendo el crecimiento, la invasión y la supervivencia de las células tumorales.

Sin embargo, en la angiogénesis maligna inducida por el VEGF los nuevos vasos presentan un desorden marcado, ausencia de pericitos, alteración en el flujo sanguíneo y aumento de la permeabilidad vascu$\operatorname{lar}^{25}$. Todas estas anomalías morfológicas y funcionales provocan una mala oxigenación del tumor. Es sabido que la RT depende de la presencia de oxígeno para provocar la muerte celular tumoral, por lo que la inhibición de la angiogénesis resulta una estrategia atractiva para mejorar los resultados de la RT.

\section{Efectos de la radiación sobre la vasculatura}

La radiación puede ejercer un efecto local y sistémico sobre la angiogénesis. Se 
ha comprobado que tras irradiar células tumorales se produce un aumento en la expresión de factores proangiogénicos tales como el VEGF ${ }^{26}$ como una reacción de supervivencia. El VEGF posee actividad an- tiapoptótica o prosupervivencia, promueve la hipoxia e induce radiorresistencia, lo que lo convierte en una diana terapéutica potencialmente útil para ser bloqueado durante la RT (Fig. 2).

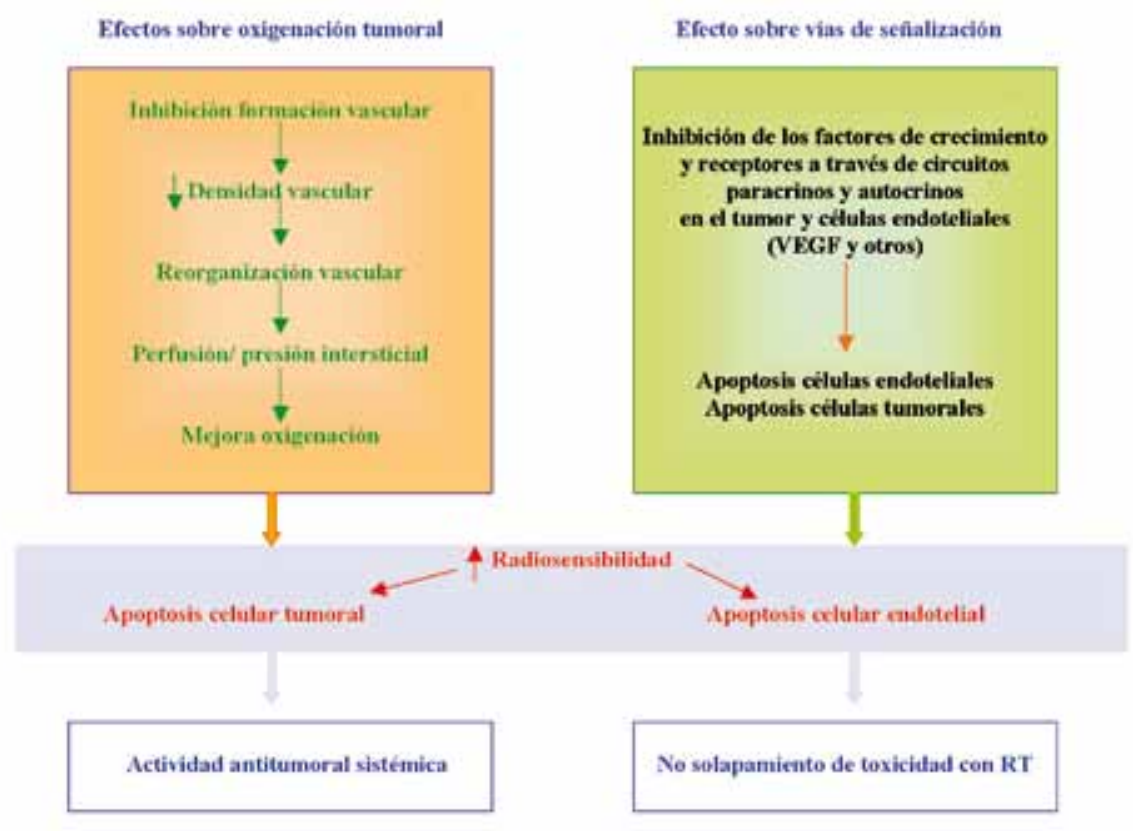

Figura 2. Mecanismos de interacción entre los agentes antiangiogénicos y la radiación. Efectos sobre la oxigenación tumoral, vías de señalización, radiosensibilidad y control de la actividad tumoral sistémica.

\section{INHIBICIÓN DE LA ANGIOGÉNESIS EN ASOCIACIÓN CON RADIOTERAPIA}

\section{Datos preclínicos}

Se han estudiado múltiples agentes antiangiogénicos combinados con RT, entre ellos, bevacizumab, SU6668, SU5416, TNT470, PKT787, SU11248, angiostatina, etc.

Aunque las investigaciones iniciales reflejaban el temor a que la inhibición de la angiogénesis pudiese desencadenar hipoxia y consecuentemente resistencia a la RT, la evidencia más reciente apoya lo contrario. Los compuestos antiVEGF han de- mostrado en diversos modelos tumorales como el adenocarcinoma de colon, carcinoma escamosos de cabeza y cuello, carcinoma de pulmón o gliomas, una normalización de la vasculatura tumoral, mejoría de la oxigenación, inhibición de la liberación de VEGF en respuesta al estrés generado por la radiación, inhibición del crecimiento tumoral y reducción de la dosis de RT requerida para el control de los tumores. Todavía no se conoce la secuencia óptima de administración de estos tratamientos, pero los datos apuntan a que el mayor beneficio 
pueda quizá obtenerse administrando los inhibidores de VEGF concurrentemente o después de la $\mathrm{RT}^{27,28}$.

Por otra parte, el EGFR juega un papel importante en la expresión de VEGF y por lo tanto en la angiogénesis. El bloqueo de EGFR conjuntamente con VEGF es una estrategia interesante que ha dado buenos resultados en investigación preclínica en conjunción con $\mathrm{RT}^{29}$.

\section{Datos clínicos}

Con varios fármacos se han obtenido ya resultados positivos, bien administrados de forma aislada o combinados con QT. Es el caso del bevacizumab en CCR, CM y CPNM, o de sorafenib y sunitinib en el CRCC. Sin embargo, la evidencia con RT es todavía tan escasa como incipiente. El agente más estudiado ha sido bevacizumab y la experiencia de que se dispone se limita a estudios fase I/II asociado a RT con o sin QT en cáncer de recto, páncreas, sarcoma de partes blandas o CPNM. Algunos estudios incorporan ya simultáneamente inhibidores de EGFR y VEGF a las terapias convencionales de quimiorradioterapia con resultados alentadores.

De todos estos estudios se desprende que los compuestos antiangiogénicos al asociarse con RT producen un efecto aditivo o sinérgico, aunque la toxicidad añadida parece escasa, no están exentos de riesgos y pueden provocar hipertensión arterial, hemorragias y trombosis. La investigación en este área está en gran auge y es posible que un futuro próximo forme parte del tratamiento estándar de distintos tumores, junto con otros agentes biológicos, QT y RT.

\section{BIBLIOGRAFÍA}

1. Hanahan D, Weinberg RA. The hallmarks of cancer. Cell 2000; 100: 57-70.

2. Peggs K. Mackinon S. Imatinib mesylate the new gold standard for treatment of chronic myeloid leukaemia. N Engl J Med 2003; 348: 1048-1050.

3. Brigette BY. Ma, Bristow RG, Kim J, Siu LL. Combined- modality treatment of solid tumors using radiotherapy and molecular targeted agents. J Clin Oncol 2003; 21: 2760-2776.

4. Schimdt-Ullrich RK, Contessa JN, Dent P. Molecular mechanism of radiation- induced accelerated repopulation. Radiat Oncol Investig 1999; 7: 321-330.

5. Steel GG, Peскнам MJ. Exploitable mechanism incombined radiotherapy-chemotherapy: The concept of additivity. Int J Radiat Oncol Biol Phys 1979; 5: 85-91.

6. Salomon DS, Brandt R, Ciardello F. Epidermal growth factor related peptides and their receptors in human malignancies. Crit Rev Oncol Hematol 1995; 19: 183-232.

7. Tateishi M, Ishida T, Kohdono S, Hamatake M, Fukuyama Y, Sugimach K. Prognostic influence of the co-expression of epidermal growth factor receptor and c- erbB-2 protein in human lung adenocarcinoma. Surg Oncol 1994; 3. 109-113.

8. Sheridan MT, O'Dwyer T, Seymour CB. Potential indicators of radiosensitivity in squamous cell carcinoma of the head and neck. Radiat Oncol Investig 1997; 5: 180-186.

9. Rogers SJ, Harrington KJ, Eccles SA, Nutting CM. Combination epidermal growth factor receptor inhibition and radical radiotherapy for NSCLC. Expert Rev Anticancer Ther 2004; 4: 569-583.

10. Pietras RJ, Poen JC, Gallardo D. Monoclonal antibody to HER-2 / neuroreceptor modulates repair of radiation- induced DNA damage and enhances radiosensitivity of human breast cancer cells overexpresssing this oncogene. Cancer Res 1999; 59: 1347-1365.

11. Bowers G, Reardon D, Hewitt T. The relative role of ErbB1-4 receptor tyrosine kinases in radiation signal transduction responses of human carcinoma cells. Oncogene 2001; 20: 1388-1397.

12. HUANG SM, HaRARI PM. Modulation of radiation response after epidermal growth factor receptor blockade in squamous cells carcinomas. Inhibition of damage repair, cell cycle kinetics and tumor angiogenesis. Clin Cancer Res 2000; 6: 2166-2174.

13. HaRARI PM, ALLEN GW, BonNer JA. Biology of interactions: antiepidermal growth factor receptor agents. J Clin Oncol 2007; 25: 4057-4065.

14. Prat A, Baselga J. Bioterapia: aplicaciones actuales y futuras en oncología. Med Clin 2007; 129: 184-193.

15. Bonner JA, Harari PM, Giralt J, Azarnia N, Shin DM, COHEN RB et al. Radiotherapy plus cetuximab for squamous-cell carcinoma of the head and neck. N Engl J Med 2006; 354: 567-578. 
16. Crombet T, Osorio M, Cruz T, Roca C, Del CasTILLO R, Mon R et al. Use of the humanized anti-epidermal growth factor receptor monoclonal antibody h-R3 in combination with radiotherapy en the treatment of locally advanced head and neck cancer patients. J Clin Oncol 2004; 22: 1646-1654.

17. Jensen AD, Munter MW, Bischoff $\mathrm{H}$, Haselmann R, Timke C, Krempien R, Sterzing F et al. Treatment of non.small lung cancer with intensity modulated radiation therapy in combination with cetuximab: the NEAR protocol (NCT00115518). BMC Cancer 2006; 6: 122-129.

18. Hughes S, Liong J, Miah A, Ahmad S, Leslie M, HaRper P, Prendiville J et al. A brief report on the safety study of induction chemotherapy followed by synchronous radiotherapy and cetuximab in stage III non-small cell lung cancer (NSCLC): Scratch study. J Thorac Oncol 2008; 3: 648-651.

19. Blumenschein GR, Paulus R, Curran WJ, Robert F, Fossella FV, Werner-Wasik M et al. A phase II study of cetuximab (C225) in combination with chemoradiation (CRT) in patients (PTS) with stage IIIA/B non-small cell lung cancer (NSCLC): A report of the 2 year and median survival (MS) for the RTOG 0324 trial. J Thorac Oncol 2007; 2: S342-S343: Abstract B3-07.

20. Martínez E, Martínez M, Viñolas N, Casas F, de la Torre A, Valcarcel $F$ et al. Feasibility and tolerability of the addition of erlotinib to 3D thoracic radiotheraphy (RT) in patients with unresectable NSCLC: A prospective randomized phase II study. J Clinic Oncol 2008; 26 (15S): Abstract 7563.

21. Chinnaiyan P, Allen GW, Harari PM. Radiation and new molecular agents: targeting HDAC,
HSP90, IGF-1R, PI3K and Ras. Semin Radiat Oncol 2006; 16: 59-64.

22. McKenna WG, Muschel RJ, Gupta AK. The Ras signal transduction pathway and its role in radiation sensitivity. Oncogene 2003; 22: 5866-5875.

23. BRunNer TB, GuPTA AK, SHI Y. Farnesiltransferase inihibitors as radiation sensitizers. Int $\mathrm{J}$ Radiat Biol 2003; 79: 569-576.

24. Folkman J. Seminars in medicine of the Beth Israel Hospital, Boston; Clinical applications of research on angiogenesis. N Engl J Med 1995; 333: 1757-1763.

25. O'ReILly MS. Radiation combined with antiangiogenic and antivascular agents. Semin Radiat Oncol 2006; 16: 45-50.

26. Gorski DH, Beckett MA, Jaskowiat NT. Blockage of the vascular endotelial growth factor stress response increases the antitumor effects of ionizing radiation. Cancer Res 1999; 59: 3374-3378.

27. Kozin S, Boucher Y, Hicklin DJ. Vascular endothelial growth factor receptor-2-blocking antibody potentiates radiation-induced longterm control of human xenografts. Cancer Res 2001; 61: 39-44.

28. Ning S, LAIRD D, Cherrington JM. The antiangiogenic agents SU5416 and SU6668 increased the antitumor effects of fractionated irradiation. Radiat Res 2002; 157: 45-51.

29. Raben D, Helfrich B, Bunn P. Targeted therapies for non-small-cell lung cancer: biology, rationale and preclinical results from a radiation oncology perspective. Int J Radiat Oncol Biol Phys 2004; 59: 27-38. 
